\title{
Fatores a Serem Considerados para o Lançamento de Nova Marca de Café Orgânico
}

\author{
Dayanny Carvalho Lopes. ${ }^{1}$, Prof. Dr. José Messias Miranda ${ }^{2}$, Prof. Dr. André Delly Veiga ${ }^{3}$. \\ ${ }^{1}$ Instituto Federal de Ciência e Tecnologia do Sul de Minas Campus Pouso Alegre \\ dayanny.lopes@ifsuldeminas.edu.br \\ ²Universidade José do Rosário Vellano - Unifenas, Alfenas MG - Jose.miranda@unifenas.br \\ ${ }^{3}$ Instituto Federal de Ciência e Tecnologia do Sul de Minas Campus Machado -
}

\section{RESUMO}

A demanda por produtos orgânicos aumenta no mundo todo e gera oportunidades de mercado em diversas regiões do planeta. Cria oportunidades, principalmente para pequenos e médios produtores, incluindo comunidades de agricultores familiares e vários outros componentes da cadeia produtiva, o que pode auxiliar o desenvolvimento de áreas rurais próximas aos grandes centros urbanos e a corredores de exportação. Percebe-se que os consumidores estão mais preocupados com a questão relacionada à saúde e meio ambiente. Com relação a isso o mercado está carente de produtos voltados para a sustentabilidade. Em face da preocupação dos consumidores com o bem-estar, a Coopfam colocará no mercado um novo produto sustentável: o café orgânico DaTerra. Em razão disto foi realizada uma pesquisa para verificar os fatores a serem considerados para o lançamento do novo produto. O principal objetivo desse estudo foi analisar os fatores a serem considerados para o lançamento da marca de café no mercado. A pesquisa descritiva foi realizada nos principais supermercados de Machado e Poço Fundo/ MG, com a ajuda de um questionário. Os resultados demonstraram que campanhas institucionais de esclarecimento devem ser formuladas, devido à pouca informação que os consumidores possuem sobre os cafés orgânicos e as estratégias para o lançamento do produto deverão ser voltadas para os consumidores que desconhecem um produto orgânico.

Palavras-chave: Comunicação, Marcas, Marketing, Café Orgânico.

\section{Factors to be Considered for the Launch of a New Brand of Organic Coffee}

\begin{abstract}
The demand for organic products increases worldwide and creates market opportunities in various regions of the world, especially for small and medium producers, including communities of family farmers and various other components of the production chain, which may help the development of rural areas close to large urban centers and export corridors. It is observed that consumers are more concerned with issues related to health and environment, and in this regard the market lacks sustainable products. In face of the consumers' concern about welfare, Coopfam will launch onto the market a new sustainable product: DaTerra organic coffee. A research was then carried out in the supermarkets of Machado and Poço Fundo, MG, by means of a questionnaire, to verify the factors to be considered for launching a new product, as is the main purpose of this study: to launch a new brand of coffee. The results showed that institutional clarification campaigns should be formulated, due to the lack of information of consumers with regard to organic coffee, and strategies for launching this product will aim at consumers who are unaware of organic products.
\end{abstract}

Keywords: Communication, Brand, Marketing, Organic Coffee. 


\section{INTRODUÇÃO}

É crescente a preocupação da sociedade com a saúde, a qualidade de vida e do meio ambiente, levando os consumidores a valorizarem a adoção de métodos de produção agrícolas que garantam a qualidade dos produtos e que sejam menos agressivos ao meio ambiente e socialmente justos com os trabalhadores rurais. É neste contexto que a agricultura orgânica surge como alternativa para produção agrícola mais sustentável, ambientalmente equilibrada e socialmente justa (SAES et al, 2002).

A demanda por produtos orgânicos aumenta no mundo todo e gera oportunidades de mercado em diversas regiões do planeta. Cria oportunidades, principalmente para pequenos e médios produtores, incluindo comunidades de agricultores familiares e vários outros componentes da cadeia produtiva, o que pode auxiliar o desenvolvimento de áreas rurais próximas aos grandes centros urbanos e a corredores de exportação (NEVES et al., 2004).

A busca por atributos diferenciados em produtos agroindustriais está mostrando um crescimento constante na última década, fruto de mudanças nas preferências dos consumidores. Há consumidores dispostos a pagar mais por produtos que possuem alguns atributos desejados. A possibilidade de diferenciação e segmentação de produtos é um entre os fatores mais relevantes que nos últimos anos estão influenciando a competitividade dos produtos agroindustriais. Em conseqüência disso, alguns atributos de qualidade, passíveis de certificação, estão sendo incorporados, como instrumento de concorrência do produto final. Além disso, a crescente demanda, particularmente em países desenvolvidos, por produtos saudáveis e socialmente corretos, possibilitam o surgimento de produtos diferenciados, com novos atributos.

O principal objetivo desse estudo foi avaliar os fatores considerados para o lançamento da nova marca de café orgânico no mercado e o objetivo específico, caracterizar os fatores para o lançamento da nova marca de café.

\section{REFERENCIAL TEÓRICO}

A diferenciação de produtos pode ser entendida como uma busca de liderança por qualidade, aqui definida como a presença de determinados atributos desejáveis pelos consumidores (PEREIRA et al, 2004). As diferenças entre os produtos podem ser reais ou imaginadas, tangíveis ou intangíveis. No caso de diferenciação de commodities pode haver de fato uma pequena diferença real no produto. Mas as bases para a diferenciação também podem estar relacionadas a uma imagem a ele associada, ao seu lugar de origem, ou ainda ao uso exclusivo de um nome (KOTLER, 2000).

Atualmente busca-se adequar mais o marke- ting no contexto do agronegócio. Apesar de utilizarem os mesmos conceitos, consideram-se algumas particularidades das firmas agroalimentares como a natureza dos produtos, características de demanda, comportamento do consumidor, dispersão do setor agropecuário, concentração do setor de distribuição e importância dos sistemas cooperativistas. A tendência apresentada é uma abordagem sistêmica que propõe um trabalho com as cadeias agroindustriais de trás para frente, identificando o consumidor final, suas características e padrões de referencias, pois ele é o elemento dinamizador das cadeias agroindustriais modernas. Na busca de satisfazer o mercado-alvo dentro de um determinado prazo, a empresa planeja, implementa e controla um conjunto de variáveis mercadológicas (SILVA; BATALHA, 1997).

As exigências dos consumidores de café vêm aumentando ao longo dos anos e o Brasil, maior produtor mundial, mostrou-se extremamente acomodado no que diz respeito ao tratamento mercadológico desse produto. A maioria dos produtores, exportadores e segmentos políticos não souberam realizar campanhas de marketing eficazes para valorizar a imagem do produto brasileiro. O problema é mais complexo do que parece, não sendo o único defeito, a ausência de marketing (PEREIR et al, 2004).

\section{Café Orgânico}

Apesar da pequena porcentagem que representa em relação à cafeicultura brasileira, o café orgânico é uma atividade com enorme potencial de promover a preservação ambiental e valorização social e econômica de uma região e representa uma ótima oportunidade para fortalecer as organizações de pequenos produtores e reduzir as desigualdades sociais (SAES et al., 2002).

O café orgânico é cultivado sob as regras da agricultura orgânica, que tem como objetivo o fortalecimento dos processos biológicos, por meio de diversificação de culturas, fertilização com adubos orgânicos e controle biológico de pragas. Esse conceito apresenta fortes características de preservação ambiental, mas também considera aspectos econômicos e sociais da produção agrícola, porém com ênfase menor que nos produtos fair trade (comércio justo) (SAES et al., 2002).

Também conhecido como café ecológico, é geralmente cultivado em sistema de produção sombreado. Estudo realizado por Harkaly et al. (1997) com produtores orgânicos de café de Minas Gerais mostra sistemas de produção de café consorciados com milho e feijão, com uso intensivo de mão de obra. Os autores demonstram a viabilidade técnica e econômica dos cultivos orgânicos em relação aos convencionais. A colocação do produto num mercado diferenciado, no entanto, é apontada como o principal componente de sua viabilidade econômica. O café é um dos produtos 
orgânicos mais importantes exportados pelos países em desenvolvimento. Em 1997 foi autorizada pela União Européia a importação de 69 toneladas de café verde orgânico do México e 35 toneladas da Costa Rica. O café orgânico pode ser encontrado em lojas especializadas e supermercados da Alemanha, Dinamarca, França, Holanda, Inglaterra, Suécia e Suíça (UNCTAD, 1999).

O cultivo de café orgânico segue regras próprias do sistema orgânico de produção, cujo mercado interno e externo vem se expandindo muito rapidamente. Abrem-se assim novas perspectivas na economia rural brasileira, principalmente para os pequenos produtores.

Para o café ser rotulado como orgânico, tanto sua produção como seu processamento precisam ser monitorados por certificadores credenciados. Nos países exportadores de produtos orgânicos, a certificação pode se feita por organizações locais, por parcerias entre agências locais e internacionais, por organizações internacionais, ou por uma de suas filiais. Em alguns casos, os serviços de certificação podem ser sub-contratados ou ainda podem ser realizados por grupos de pequenos produtores, desde que sejam desenvolvidos mecanismos de inspeção e de controle interno conforme os padrões da agricultura orgânica (UNCTAD, 1999).

\section{O Mercado de Café Orgânico}

O mercado de produtos orgânicos é predominantemente constituído por consumidores conscientes das questões ligadas à saúde e questões de caráter ambiental e social.

A agricultura orgânica ganha cada vez mais espaço na economia mundial. O segmento de produtos orgânicos tem crescido cerca de $20 \%$ ao ano, tanto em países desenvolvidos como em desenvolvimento é o segmento que mais cresce dentro do setor de alimentos. (YUSSEFI \& WILLER, 2003).

O consumo de cafés especiais, como o café orgânico, gourmet, sombreados e socialmente justos, também está aumentando. Os preços destes cafés no mercado nacional e internacional são mais atraentes para os produtores, como consequência de suas características de produção, qualidade e menor oferta (RICCI et al., 2002).

O mercado internacional de café orgânico é dominado pelo México, que comercializa mais de 30 mil toneladas ao ano e é o maior produtor, com uma área estimada em 70.838 ha $(10,4 \%$ de toda a área cultivada com café naquele país) (YUSSEFI \& WILLER, 2003). Peru (onde $30 \%$ da produção de café é orgânica), Bolívia, Colômbia, Nicarágua, Guatemala e Costa Rica são também importantes produtores de café (RICCl et al., 2002).

De acordo com Caixeta e Pedini (2002), a cafeicultura orgânica no Brasil tem mantido taxas de cres- cimento próximas a $100 \%$ ao ano e ocupa uma área de 13.000 ha e mais de 419 produtores. Entretanto, é preciso investir esforços na produção de café orgânico, aliando qualidade e sustentabilidade socioambiental, garantindo assim competitividade nas exportações.

Agricultura orgânica é o sistema de manejo sustentável da unidade de produção com enfoque sistêmico que privilegia a preservação ambiental, a agrobiodiversidade, os ciclos biogeoquímicos e a qualidade de vida humana (RICCl et al., 2002). Este tipo de agricultura aplica os conhecimentos da ecologia no manejo da unidade de produção, baseada numa visão holística da unidade de produção. Isto significa que o todo é mais do que os diferentes elementos que o compõem. A unidade de produção é tratada como um organismo integrado com a flora e a fauna. Portanto, é muito mais do que uma troca de insumos químicos por insumos orgânicos/biológicos/ ecológicos (RICCl et al., 2002).

O café orgânico é um produto diferenciado, de maior valor agregado, cujo mercado tem crescido e se fortalecido ao longo dos anos (CAIXETA, 2000).

\section{Marketing}

Segundo Kotler \& Keller, 2006 as marcas identificam a origem ou o fabricante de um produto e permitem que os consumidores -sejam indivíduos ou organizações - atribuam a responsabilidade pelo produto a determinado fabricante ou distribuidor. Os consumidores podem avaliar um produto idêntico de forma diferente, dependendo de como sua marca é estabelecida. Eles conhecem as marcas por meio de experiências anteriores com o produto e do programa de marketing do produto.

A função da comunicação de marketing é o meio pelo qual as empresas buscam informar, persuadir, e lembrar os consumidores - direta ou indiretamente - sobre os produtos e marcas que comercializam. Num certo sentido, a comunicação de marketing representa a 'voz' da marca e é o meio pelo qual ela estabelece um diálogo e constrói relacionamentos com os consumidores (KOTLER; KELLER, 2006).

A cor não é o único fator que auxilia a embalagem a promover venda, mas é uma parte importante de todo o processo. A cor exerce uma influência muito grande na vida de cada um e disso ninguém duvida. Não se compra apenas pela cor, ela não é um produto. Em geral, nos relacionamos com a cor de maneira subjetiva, embora esteja sempre ligada a algo físico ou imaginada em pensamentos (DANGER, 1973).

Dentro de uma visão integrada de planejamento do marketing no agronegócio, são muitos os fatores que estabelecem uma perspectiva de crescimento de consumo de um certo produto. Dentre as ações de planejamento de marketing pode-se destacar a segmentação de mercado (MEGIDO; XAVIER, 2003). 
Para Karsaklian (2000), segmentação de mercado é dividir um mercado em grupos de compradores potenciais, que tenham semelhantes necessidades e desejos, percepção de valores ou comportamento de compra. O mercado de café, tanto no Brasil quanto no resto do mundo, parece estar se segmentando por si próprio uma vez que são poucas as iniciativas concretas neste sentido. O consumidor, cada vez mais exigente, passa a ditar as regras daquilo que ele quer comprar.

Uma vez que o produtor de café, ou a indústria de torrefação, tenha definido seu mercado alvo, é preciso posicionar o produto nesse mercado. Isto significa que um produto deve conseguir ocupar lugar claro, distinto e desejável, em relação ao produto dos concorrentes na mente dos consumidores. Para Koltler (2000), "posicionamento é o ato de desenvolver a oferta e a imagem da empresa, de maneira que ocupe uma posição competitiva distinta e significativa na mente dos consumidores".

É importante identificar as diferenças realmente importantes para o consumidor, levando-se em conta suas percepções, impressões e seus sentimentos, para que resultem em benefícios percebidos, difíceis de ser copiados pelos concorrentes, compatíveis com o poder de compra dos consumidores e que agreguem valor ao produto, sendo lucrativo à empresa ou ao produtor. É possível posicionar um produto com base em um ou mais fatores de diferenciação, mas o posicionamento com base em muitos fatores pode gerar confusão ou descrença para o consumidor.

Zylbersztajn e Farina (2001) conceituaram as formas de diferenciação para o café:

\begin{abstract}
"O conceito de café especiais está intimamente ligado ao prazer proporcionado pela bebida. Destacam-se por algum atributo especifico atribuído ao produto, ao processo de produção ou ao serviço a ele associado. Diferenciam-se por características como qualidade superior da bebida, aspecto dos grãos, forma de colheita, tipo de preparo, historia, origem dos plantios, variedades raras e quantidades limitadas, entre outras. Podem também incluir parâmetros de diferenciação que se relacionam à sustentabilidade econômica, ambiental e social da produção, de modo a promover maior equidade entre os elos da cadeia produtiva. Mudanças no processo industrial também levam à diferenciação, com adição de substancias, como aromatizados, ou com sua subtração, como os descafeinados. A rastreabilidade e a incorporação de serviços também são fatores de diferenciação e, portanto, de agregação de valor".
\end{abstract}

Cabe a cada produtor ou torrefador, no caso de se embrenharem pelo mundo dos cafés diferenciados, descobrir suas aptidões e encaixar em um destes segmentos. A diferenciação revela um mercado em plena ascendência e segmentá-lo não é tarefa para ser desenvolvida isoladamente e sim em cooperação com entidades públicas e privadas do sistema agroindustrial do café. Para que esta estratégia de diferenciação seja eficaz, é importante que o produtor ou a empresa considerem os desejos e as necessidades dos consumidores. Os atributos diferenciadores só terão real valor se os consumidores perceberem e aprovarem essas mudanças (PEREIRA et al., 2004).

\section{MATERIAL E MÉTODOS}

Para atingir os objetivos propostos a pesquisa foi realizada por meio de dados secundários e primários. O estudo proposto possui caráter descritivo e qualitativo. Foi realizada uma pesquisa exploratória, na qual se buscou verificar os fatores a serem considerados para o lançamento da nova marca de café no mercado. A metodologia adotada partiu dos indícios dados pelos processos levantados na pesquisa bibliográfica, adaptada para se encaixar nas restrições a que este trabalho esteve exposto.

\section{Coleta de dados}

A coleta de dados aconteceu em duas etapas consecutivas. A primeira foi preparatória e a segunda etapa foi a execução (coleta de dados).

A fase preparatória consistiu na "entrada em cena" do ambiente organizacional. Esta introdução se deu por intermédio de uma comunicação formal, autorizando a pesquisa de documentos e acesso às informações necessárias. Por um período de duas semanas, acompanhou-se o processo de integração na empresa, como se fosse um novo funcionário. Durante esse período, a principal fonte de coleta de dados foi a observação direta. Em conjunto com a observação direta, foi possível conversar o gerente da Cooperativa para verificar quais seriam os procedimentos adotados para o lançamento do novo produto.

Para a segunda fase, a coleta de dados, utilizaram-se entrevistas através de questionários, com os consumidores nos locais de compra para definir quais fatores influenciam no momento da compra do produto, com questionário semiestruturado. Em seguida, o tema foi aprofundado, sendo questionada a opinião do entrevistado sobre o assunto. Abordados todos os aspectos da entrevista, uma pergunta do tipo geral foi realizada. O levantamento de dados foi realizado com a população das cidades de Machado e Poço Fundo/MG, visto que a cidade de Machado possui uma população estimada de 38.684 habitantes e Poço Fundo possui 15.961 habitantes (IBGE, 2010).

Para coletas de dados através da aplicação do questionário foram realizadas abordagens em 4 supermercados de Machado e 2 supermercados em Poço Fundo (sendo que estes supermercados são os que possuem maior movimento), entre os dias 27 de setembro e 02 de outubro de 2010. A amostra foi selecionada 
por conveniência nos supermercados.

Os questionários foram aplicados a 250 pessoas, sendo que 175 na cidade de Machado e as outras 75 na cidade de Poço Fundo.

A organização dos dados foi feita computandose as frequências percentuais sendo representados através dos gráficos de colunas e setores.

\section{RESULTADOS E DISCUSSÃO}

$\mathrm{Na}$ avaliação quanto ao gênero dos participantes da pesquisa, mostra-se bem dividida: $45,2 \%$ do sexo masculino e $54,8 \%$ do sexo feminino, invalidando os veIhos paradigmas de que apenas, ou na grande maioria das vezes, as compras são realizadas pelo sexo feminino.

Um resultado importante foi o constatado em relação à faixa etária, nota-se uma maioria de pessoas acima de 46 anos, confirmando Kotler (2006), que relata que os jovens não possuem tradição e hábito de fazer compras destinadas à alimentação e higiene do lar, deixando essa tarefa a cargo dos adultos.

Quando questionados sobre o consumo de café, $70 \%$ consomem a bebida rotineiramente e os outros $30 \%$ não consomem, mas já experimentaram alguma vez.

Ao avaliar sobre a quantidade de xícaras de café consumidas diariamente, $38 \%$ consomem até 3 xícaras ao dia, $30 \%$ dos entrevistados consomem de 3 a 5 xícaras, e $32 \%$ dos entrevistados consomem mais de 5 xícaras por dia e nenhuma pessoa declarou que não toma café.

Em relação aos horários que melhor caracterizam o consumo de café $37,2 \%$ o fazem na hora do lanche e refeições, $48 \%$ disseram que tomam café sempre que tem vontade, $10 \%$ bebem café em reuniões de trabalho e/ou encontros sociais e $5 \%$ tomam café sempre que fumam. Analisado o hábito de consumo de café, percebe-se que os consumidores não deixam de tomar o café diariamente e sempre que possível procuram tomar a bebida.

Quanto aos critérios mais utilizados na escolha de um café na hora da compra (GRÁF. 1), o sabor (25\%) e a marca (23\%) são os mais importantes, seguidos do preço $(17 \%)$, qualidade $(17 \%)$, aroma $(8 \%)$, selo $A B I C$ (8\%), e embalagem (2\%). Dentre os critérios para a decisão de compra dos entrevistados. Isto mostra que o consumidor escolhe o café pelo sabor relacionado à marca na hora da compra, mostrando que não é fácil adentrar neste mercado rapidamente. É preciso fazer um trabalho de marketing para o café ocupar mais espaço nos meios de comunicação, focando a marca e a embalagem para atrair a atenção dos consumidores.

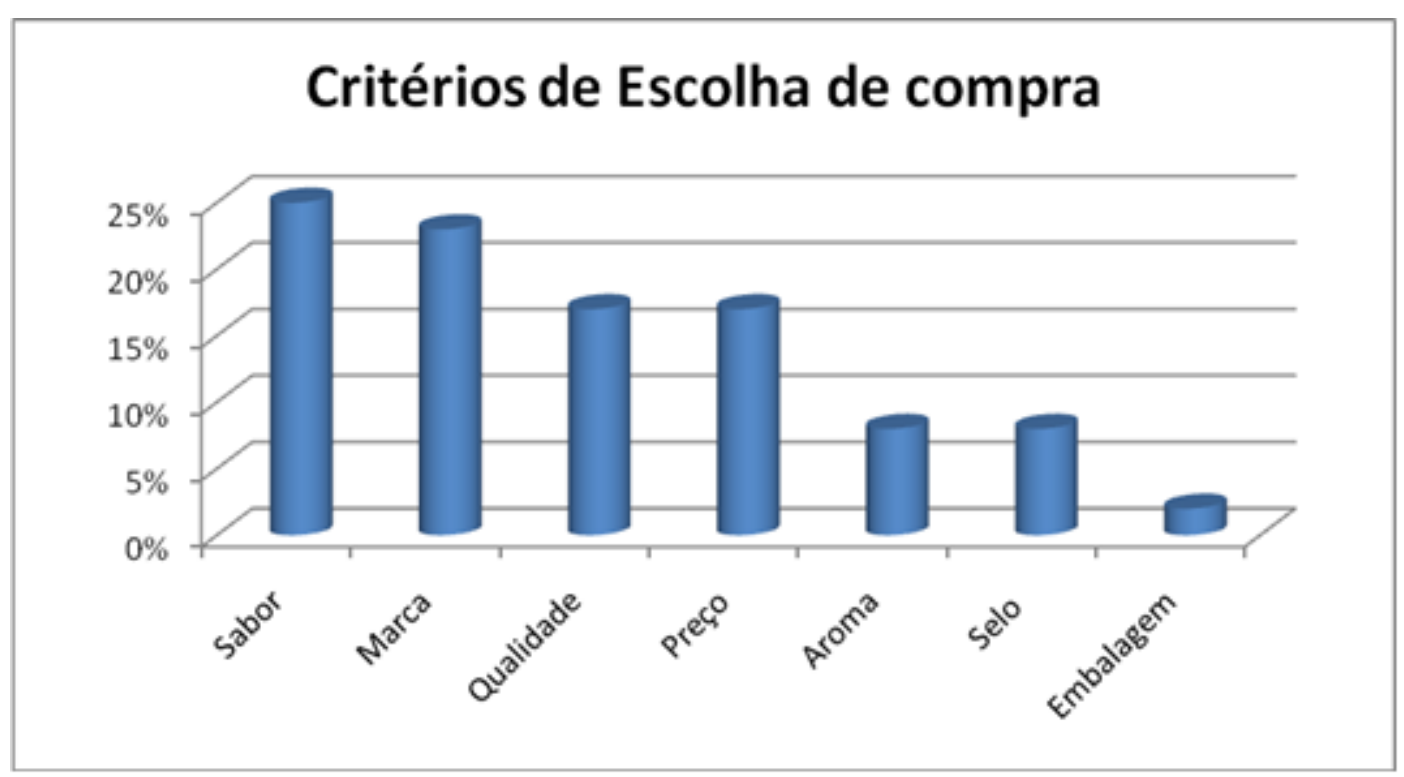

GRÁFICO 1 - Critérios de escolha de compra do café.

Questionados se conhecem o selo de pureza ABIC, $79,2 \%$ dos consumidores responderam que conhecem e os outros $20,8 \%$ não conhecem o selo ABIC. Uma maioria significante conhece o selo, sendo importante porque mostra que o consumidor se preocupa com a qualidade da bebida e a imagem do café. A pesquisa revelou que $62 \%$ levam em consideração o selo $A B I C$ na hora da compra e $38 \%$ não se preocupam com o selo $A B I C$, demonstrando que o selo significa confiabilidade na hora da escolha de compra do café.

Os consumidores de café entrevistados mostraram que são tradicionais quando vão comprar o café no supermercado; $85 \%$ preferem comprar o café torrado e moído, $8 \%$ buscam o café instantâneo, 3\% procuram comprar cafés especiais, $3 \%$, cappuccino e $1 \%$ prefere o café em grãos para a máquina de espresso.

Dentre os produtos com o mesmo preço, o fator 
que leva à decisão de escolha do produto ficou com a marca $(80 \%)$, seguido da qualidade, $10 \%$, embalagem, $9 \%$, e tipo de embalagem, $1 \%$. Este resultado reflete a importância da marca na venda do produto, a lealdade dos consumidores à marcas tradicionais e as marcas com um forte apelo de propaganda.
Como a maioria dos entrevistados compra o café que é consumido em casa, procurou-se saber sobre o grau de importância das características do café. A Tabela 1 mostra que o critério mais importante na escolha do café foi o sabor, com $86 \%$ das opiniões, seguido pelo aroma $(72 \%)$ e a cor da bebida $(41 \%)$, fator importante no critério de escolha.

TABELA 1 - Critério de escolha do café segundo os entrevistados

\begin{tabular}{|c|c|c|}
\hline Fator & Grau de Importância & ImportânciaPercentual (\%) \\
\hline \multirow{2}{*}{ Sabor } & Muito importante & 86 \\
& Importante & 13 \\
& Pouco importante & 1 \\
\hline \multirow{2}{*}{ Aroma } & Muito importante & 25 \\
& Importante & 3 \\
\hline \multirow{3}{*}{ Cor da bebida } & Pouco importante & 33 \\
& Muito importante & 41 \\
& Importante & 26 \\
\hline
\end{tabular}

Ao perguntar se o consumidor estaria disposto a pagar mais por um café de qualidade, a grande maioria $(90 \%)$ afirmou que sim, confirmando que os consumidores estão exigentes com relação à qualidade de vida, consumindo produtos que tenham custo/beneficio e lhe tragam prazer.

Apesar de a região pesquisada ser produtora de café orgânico, a maioria dos entrevistados (60\%) não conhece café orgânico e não sabe como é a produção do mesmo. Isso indica que é necessário realizar campanhas de marketing para ocupar um espaço na mente do consumidor, desse tipo de café, trabalhando o mercado e fortalecer a marca. De acordo com a pesquisa $80 \%$ disseram que nunca compraram ou viram café orgânico em algum supermercado, mostrando que a campanha de marketing deve ser feita não somente com relação aos consumidores, mas também para os varejistas que ainda não tem conhecimento desse tipo de café. Entende-se como campanha de marketing direcionada para os varejistas, não as campanhas institucionais, mas campanhas individuais para cada varejista da própria torrefadora ou produtora como as ações de merchandising dentro dos PDVs (ponto de venda), para conscientizar e apresentar o produto café orgânico aos varejistas. Como foi comprovado na pesquisa mostrada sobre cafés especiais do Instituto Pensa 2001, mostrouse que os supermercadistas sugerem que as empresas invistam em divulgação dos cafés especiais.

Ao serem questionados sobre a produção dos cafés orgânicos (sustentáveis) a grande maioria (72\%) dos consumidores demonstrou mais uma vez serem leigos no assunto e desconhecem que a produção sustentável preserva o meio ambiente e garante melhores condições de vida aos produtores.

Quando questionados a respeito da importância do visual do produto, $45,2 \%$ responderam que o visual do produto é muito importante, enquanto outros $37,8 \%$ responderam que o visual do produto é importante. Sendo assim, $82 \%$ dos consumidores consideram o visual como um pré-requisito básico para a compra de um produto. Essa importância do visual do produto para o consumidor cogita que as pessoas comparam produtos, e, em muitos casos, deixam de levar um produto com uma aparência que não o agrada. Dentre os $17 \%$ que responderam que o visual era pouco ou não importante, o principal argumento é que eles estavam mais preocupados com o preço.

Em se tratando da influencia da cor, embalagem ou local do produto, $48 \%$ dos consumidores responderam que sempre se sentem influenciados pela cor do produto, embalagem ou local, $34,4 \%$ dos consumidores disseram que nunca sentem influenciados pela cor do produto, da embalagem ou do local são, e 17,6\% dos consumidores eventualmente se sentem influenciados. Sendo assim, é perceptível que a maioria dos consumidores já estão habituados com um produto ou não presta atenção nessas variáveis.

A respeito de optar por produtos de acordo com as cores dos mesmos, $74,4 \%$ dos consumidores raramente procuram comprar produtos com suas cores preferidas, $16 \%$ responderam que sempre compram produtos com suas cores preferidas, e 9,6\% responderam 
que eventualmente o fazem. Constatou-se que os consumidores não consideram a cor como um fator determinante na escolha de um produto, mas em alguns produtos e em determinadas situações a cor se torna fator importante na escolha.

Para verificar a utilização de cores na embalagem perguntou-se "As cores utilizadas na embalagem chamam a sua atenção?", e $70 \%$ dos entrevistados responderam que as cores utilizadas nas embalagens sempre chamam a atenção, enquanto outros $20 \%$ responderam que eventualmente as cores chamam a sua atenção, e outros $10 \%$ disseram que raramente as cores da embalagem chamam atenção. Os consumidores, em sua maioria se sentem atraídos pelas cores da embalagem, o que sugere a cor como um fator importante no reconhecimento de um produto.

Sobre o tipo de embalagem para a compra do café, $74 \%$ disseram que preferem a do tipo almofada, e os outros $26 \%$ preferem o café embalado a vácuo. Estes resultados estão conforme a pesquisa da InterScience, que mostra a diminuição para a embalagem do tipo almofada e aumento para a vácuo.

Pode-se dizer que a cor é um fator importante na compra de um produto, mas existem outros fatores que também são tão ou mais importantes que o visual. Em geral, a marca é um dos fatores que facilitam o processo de troca e uma parte importante no conjunto dos fatores que interferem na decisão de compra.

\section{CONCLUSÃO}

Ao longo do estudo foram identificados diversos fatores que poderão auxiliar futuras ações no sentido de fomentar o consumo do produto e melhorar a sua eficiência e competitividade no mercado de cafés orgânicos, como o lançamento de uma nova marca de café. Este estudo foi realizado para avaliar os fatores para o lançamento do café orgânico no mercado, considerando que os consumidores estão ávidos por produtos que tragam benefícios para a saúde. Pode-se concluir que o produto será bem recebido pelos consumidores, atingindo o objetivo geral do estudo.

Os atributos que estão relacionados à experiência passada na determinação da compra são sabor e marca. A reputação e a constância de padrões levam à associação entre sabor preferido e fidelidade à marca.

Estratégias coletivas visando ao aumento do consumo geral de café deveriam aproveitar a imagem positiva do Selo de Pureza. O selo é mais importante para os cafés médios e inferiores, já que identifica apenas pureza. Os cafés especiais podem abstrair do selo, mas teriam que manter padrões bem definidos e estáveis.

Através do estudo realizado, observa-se que os consumidores preferem embalagens mais atrativas e que possuem cores mais vibrantes; logo recomenda-se que a embalagem do novo produto seja com cores que lembrem o produto e possua todas as informações necessárias.

Ações voltadas para os consumidores de café serão realizadas antes, durante e depois do lançamento do produto, uma vez que a pesquisa mostrou que a maioria deles não conhece café orgânico, sendo importante a realização de estratégias de lançamento para atrair a atenção do consumidor e fazer com que a marca fique conhecida entre os consumidores e se torne dentro de pouco tempo uma das marcas mais lembradas na região.

\section{REFERÊNCIAS BIBLIOGRÁFICAS}

BARBETA, P.A. Estatística aplicada às Ciências Sociais. 4 ed. Florianópolis: UFSC, 2001. 338p

CAIXETA, I. F. A produção de café orgânico: alternativa para o desenvolvimento sustentado - o exemplo do sul de Minas. In: ZAMBOLIM, L. (Ed.). Café: produtividade, qualidade e sustentabilidade. Viçosa: UFV, Departamento de Fitopatologia, 2000. p. 323-330.

DANGER, Eric P. A cor na comunicação. Rio de Janeiro: Fórum, 1973. p.211

IBGE- Instituto Brasileiro de Geografia e Estatística. População das Cidades - Censo 2010. Disponível em: http://www.ibge.gov.br/cidadesat/topwindow.htm?1 Acesso em: 30 de janeiro de 2011.

KARSAKLIAN, E. Comportamento do Consumidor. São Paulo: Atlas, 2000

KOTLER, Philip e KELLER, Kevin. "Administração de Marketing" - 12a Edição. São Paulo: Prentice Hall, 2006.

KOTLER, Phillip. Administração de marketing: análise, planejamento e controle. $10^{\circ}$ ed. São Paulo: Prentice Hall, 2000.

MEGIDO, J. L. T. \& XAVIER, C. Marketing e Agribusiness. São Paulo: Atlas, 2003.

NEVES, M. C. P.; RIBEIRO, R. de L. D.; PEIXOTO, R. dos G. T. Riscos associados ao uso de fertilizantes. In: ELEMENTOS de apoio para as boas práticas agrícolas e o sistema APPCC. Brasília: Campo PAS, 2004. p. 8797.

PEREIRA, Sérgio Parreiras; BARTHOLO, Gabriel Ferreira; GUIMARÃES, Paulo Tácito Gontijo. Cafés especiais: iniciativas brasileiras e tendências de consumo. Belo Horizonte: EPAMIG, 2004. 80 p. (EPAMIG. Documentos, 41).

SAES, Maria Sylvia et al.. Pequenos produtores e o segmento de cafés especiais no brasil: uma abordagem preliminar, 2002. Disponível em: http://www.iea.sp.gov. br/out/LerTexto.php?codTexto=9 Acesso em: 20 de 
outubro de 2010.

SETTE, R. de S. Estratégias de marketing para aumento do consumo de café entre os jovens. In: SIMPÓSIO DE PESQUISA DOS CAFÉS DO BRASIL, 1; 2000, Poços de Caldas, MG. Resumos... Brasília, D.F. Embrapa Café, 2000. 2v, 1490 p.

SILVA, A. L \& BATALHA, M. O. Marketing estratégico aplicado a firmas agroindustriais. In: BATALHA, M. O. Gestão agroindustrial. Atlas, 1997.

UNCTAD. Organic food and beverages: world supply and major European markets. Geneva: ITC, 1999. 271 p.

YUSSEFI, M.; WILLER, H. The world of organic agriculture 2003 - statistics and future prospects. TholeyTheley: International Federation of of Organic Agriculture Movement (IFOAM), 2003.128 p. 